\title{
Utilización potencial de clones de papa obtenidos por autofecundación como inductores de haploidia en cruzamientos $4 \times$ x $2 x$
}

\author{
Rodimiro Ortiz*; Elsa L. Camadro**; Masuru Iwanaga***
}

\section{RESUMEN}

Para estudiar el potencial como inductores de haploidía en cruzamientos 4x x 2x de seis clones obtenidos por autofecundación del inductor IvP35, se realizaron cruzamientos de los mismos con cada uno de siete cultivares tetraploides de orígenes diversos. Se identificó un clon que difirió significativamente del clon original con respecto al número de presuntos haploides por baya (4.1 vs. 1.7) y por polinización (2.93 vs. 1.61) y otro clon con alto potencial, pero que no difirió estadísticamente del IvP35.

El porcentaje de tinción del polen estuvo positivamente correlacionado con el número de presuntos haploides por baya $(\mathrm{r}=0.43)$ y por polinización $(\mathrm{r}=0.368)$, y el porcentaje de presuntos haploides sobre el total de semillas $(\mathrm{r}=0.409)$. La frecuencia de polen $2 \mathrm{n}$ estuvo correlacionada en forma altamente significativa con la producción de semillas $(\mathrm{r}=0.54)$ y el número de presuntos haploides por baya $(\mathrm{r}=0.455)$ y por polinización $(\mathrm{r}=0.490)$. Por lo tanto, es posible utilizar el análisis del polen como una técnica rápida de tamizado para detectar presuntos inductores de haploidía.

Palabras claves adicionales: haploide, ginogénesis, mancha en el embrión, cruzamientos interploides.

Aceptado para publicación: abril 2, 1994

\footnotetext{
* Biol, M.S., Ph.D. Centro Internacional de la Papa (CIP). Dir. actual: Instituto Internacional de Agricultura Tropical (IITA-Nigeria).

** Ing. Agr., M.S., Ph.D. Científico visitante en el CIP. EEA INTA Balcarce. CC 276, (7620) Balcarce, Bs. .As. Argentina. M.S., Ph.D. CIP, Dirección actual: IBPGR, Via delle Sette Chiese, Roma. Italia
} 


\section{SUMMARY \\ Potential Utilization of Potato Clones Obtained By Selfing as Inducers of Haploid in Crosses $4 \mathrm{x}$ x 2x}

To study the potential as haploid inducers in $4 \mathrm{x} x 2 \mathrm{x}$ crosses of six clones obtained by selfing the successful inducer IvP35, crosses were made between them and each of seven tetraploid cultivars of diverse origins. One clone differed significantly from the original regarding the number of potential haploids per berry (4.1 vs. 1.7) and per pollination (2.93 vs. 1.61) and another clone had high potential, although it did not differed statistically from lvP35. Pollen stainability was positively correlated with number of potential haploids per berry $(\mathrm{r}=0.43)$ and per pollination $(\mathrm{r}=0.368)$, and percentage of potential haploids over the total number of seeds $(\mathrm{r}=0.409)$. The frequency of $2 n$ pollen was highly and significantly correlated with seed set $(\mathrm{r}=0.54)$ and number of potential haploids per berry $(\mathrm{r}=0.455)$ and per pollination $(\mathrm{r}=0.490)$. Therefore, pollen analysis could be used as a rapid technique for detecting potential haploid inducers.

Additional index words: $\quad$ haploid, gynogenesis, embryo spot, interploid crosses.

El término "haploide" se utiliza para designar un individuo con el número gamético de cromosomas, que se deriva de un diploide o de un poliploide. De la papa común, Solanum tuberosum L. $(2 n=4 x=48)$, los haploides $(2 \mathrm{n}=2 \mathrm{x}=24)$ pueden originarse por el desarrollo in vivo de la oósfera no fertilizada (partenogénesis femenina o ginogénesis) 0 in vitro de una célula (generalmente la vegetativa) del grano de polen (partenogénesis masculina $\mathrm{o}$ androgénesis). A su vez, de estos haploides ginogenéticos o androgenéticos pueden obtenerse monoploides $(2 n=x=12)$, o sea individuos con un solo genoma o juego básico de cromosomas. La palabra "haploide", entonces, hace hincapié en el origen peculiar de estos materiales, que implica una excepción en el curso corriente de la alternancia de generaciones al omitirse la fertilización entre las generaciones gametofítica y esporofitica (13). 
En general, el proceso de haploidización permite al investigador beneficiarse con la herencia disómica (ya que los haploides derivan de clones tetraploides con herencia tetrasómica), explorar la variabilidad existente en individuos poliploides y ampliar la estrecha base genética de la papa cultivada mediante cruzamientos con especies silvestres diploides (las más numerosas entre los Solanum tuberosum) con las que normalmente los tetraploides no pueden cruzarse directamente por problemas en el desarrollo de endosperma híbrido $(2,5,6,10,11)$.

Para poder explotar las ventajas de la haploidización en la papa, es necesario obtener gran cantidad de haploides y asegurar, de ese modo, un nivel de diversidad genética compatible con las necesidades del mejoramiento genético.

Hougas y col. (8) diseñaron un dispositivo eficiente para seleccionar haploides ginogenéticos. Este consiste en la realización de cruzamientos $4 \mathrm{x} \times 2 \mathrm{x}$, utilizando como polinizador un clon de Solanum tuberosum Grupo Phureja que es homocigota para el gen que controla la pigmentación púrpura del tallo. Como los haploides ginogenéticos son plantas que no tienen padre, las plantitas que carecen de pigmentación son, presuntamente, haploides.

Existen varios factores que afectan la frecuencia de haploides en la descendencia de los cruzamientos $4 \mathrm{x}$ x 2x, entre ellos el genotipo del polinizador y el genotipo de la madre $(7,15)$. Por lo tanto, se puede lograr un mejoramiento notable de la frecuencia de haploidización cuando se utilizan "buenos" polinizadores sobre ciertas madres caracterizadas por su capacidad para generar haploides ginogenéticos. La herencia de la capacidad para inducir haploides es relativamente simple (3).

Hermsen y Verdenius (4) seleccionaron clones de Phureja con alta capacidad para inducir haploidía. Estos polinizadores son homocigotas dominantes para los genes que controlan la producción de una mancha púrpura en el embrión, que puede ser vista con lupa en la semilla, lo que facilita el tamizado.

El clon de S. tuberosum grupo Phureja IvP35- seleccionado por Hermsen y Verdenius- ha sido utilizado extensamente en el Centro Internacional de la Papa (CIP), de Perú. En el transcurso de los trabajos de mejoramiento genético en esa institución, se encontró que el clon IvP35 producía semilla por autofecundación, a pesar de que los Solanum diploides son autoincompatibles por poseer un sistema gametofítico de autoincompatibilidad gobernado por el locus S (9). 
Dado que es altamente deseable aumentar la eficiencia de los cruzamientos 4x x 2x en los programas de mejoramiento genético en los que se aplica el método analítico-sintético $(1,14)$, se investigó el uso potencial como inductores de haploidía de las progenies obtenidas por autofecundación del clon IvP35.

\section{MATERIALES Y MÉTODOS}

En diciembre de 1985 se sembraron 100 semillas obtenidas por autofecundación del clon IvP35 bajo condiciones de invernadero en Huancayo, Perú. En el momento de la cosecha se tomaron al azar 15 clones, que se plantaron en macetas conjuntamente con el clon IvP35.

Al comenzar la floración se tomaron muestras de polen de cada clon. Estas muestras fueron teñidas sobre un portaobjetos con una solución de carmín acético en glicerol (12). Mediante observaciones con el microscopio óptico, se determinó el porcentaje de tinción del polen y la frecuencia de polen de tamaño grande (polen $2 n$ ) en plantas que producían polen de tamaño heterogéneo.

Los clones obtenidos por autofecundación y el clon IvP35 se usaron como polinizadores en cruzamientos con siete cultivares tetraploides de diferentes constituciones genéticas. Las semillas producidas por los cruzamientos interploides $4 \mathrm{x} \times 2 \mathrm{x}$ fueron separadas de acuerdo a la presencia o ausencia del marcador "mancha en el embrión", con la ayuda de un microscopio estereoscópico. Las semillas "sin mancha" fueron consideradas presuntos haploides.

Los datos obtenidos fueron analizados estadísticamente.

\section{RESULTADOS}

Seis de los quince clones obtenidos por autofecundación del clon IvP35 fueron usados en cruzamientos, debido a que los nueve clones restantes fueron poco vigorosos y florecieron en forma escasa. Los seis clones- que florecieron 20 a 30 días más tarde que el clon IvP35mostraron variabilidad para el porcentaje de tinción del polen y producción de polen $2 \mathrm{n}$. Los valores para las dos variables mencionadas fluctuaron, respectivamente, entre $5 \%$ y $70 \%$ y menos de $1 \%$ a $10 \%$. Los valores correspondientes para el clon IvP3 5 fueron $40 \%$ y $2 \%$ (Tabla 1$)$.

En total, se polinizaron 552 flores (50\% de ellas con el clon IvP35). Mediante análisis estadístico se detectaron diferencias significativas 
entre polinizadores para el número de presuntos haploides por baya y de presuntos haploides por polinización, y el porcentaje de presuntos haploides sobre el total de semillas. No se detectaron diferencias significativas para dichos caracteres entre los progenitores femeninos (no se presentan los datos).

Cuando se comparó el clon IvP35 con la media de su progenie obtenida por autofecundación, se detectaron diferencias significativas para número de semillas por baya y número de presuntos haploides por baya. El número de semillas por baya del clon IvP35 fue igual o mayor que el de su progenie obtenida por autofecundación. En la Tabla 1 puede observarse que entre los seis clones, el clon 20 tendría el mayor potencial como inductor de haploidía, ya que en este experimento produjo 4.1 presuntos haploides por baya; este valor difiere significativamente del valor del clon IvP35 (1.7 presuntos haploides por baya). El potencial de inducción de haploidía del clon 11 también es alto (2.5 presuntos haploides por baya), pero no difiere estadísticamente del clon IvP35.

Tabla 1. Capacidad de inducción de haploidía del clon IvP35 y seis clones obtenidos por autofecundación, en cruzamientos con siete progenitores femeninos.

\begin{tabular}{cccccccc}
\hline Clones & $\begin{array}{c}\text { flores tinción } \\
\text { polin. } \\
\mathrm{N}^{\circ}\end{array}$ & $\begin{array}{c}\text { polen } \\
\%\end{array}$ & $\begin{array}{c}\text { polen } \\
\%\end{array}$ & $\begin{array}{c}\text { sem/baya } \\
\mathrm{N}^{\circ}\end{array}$ & $\begin{array}{c}\text { pres.hapl./ } \\
\text { baya } \\
\mathrm{N}^{\circ}\end{array}$ & $\begin{array}{c}\text { pres.hapl } \\
\text { poliniz. } \\
\mathrm{N}^{\circ}\end{array}$ & $\begin{array}{c}\text { pres.hapl/ } \\
\text { tot sem. } \\
\mathrm{N}^{\circ}\end{array}$ \\
\hline IvP35 & 276 & 40 & 2 & $18.0 \mathrm{a}$ & $1.7 \mathrm{~b}$ & $16 \mathrm{ab}$ & $11.1 \mathrm{bc}$
\end{tabular}

\begin{tabular}{llllllll}
$\begin{array}{l}\text { Autofec } \\
\text { clones }\end{array}$ & & & & & & & \\
9 & 60 & 10 & $<1$ & $10.2 \mathrm{ab}$ & $0.3 \mathrm{~b}$ & $0.2 \mathrm{~b}$ & $1.9 \mathrm{c}$ \\
11 & 47 & 10 & $<1$ & $3.6 \mathrm{~b}$ & $2.5 \mathrm{ab}$ & $1.6 \mathrm{ab}$ & $56.9 \mathrm{a}$ \\
20 & 42 & 60 & $5-10$ & $18.1 \mathrm{a}$ & $4.1 \mathrm{a}$ & $2.9 \mathrm{a}$ & $23.2 \mathrm{~b}$ \\
40 & 34 & 5 & $<1$ & $7.5 \mathrm{ab}$ & $1.8 \mathrm{~b}$ & $1.1 \mathrm{~b}$ & $18.0 \mathrm{bc}$ \\
53 & 51 & 30 & 1 & $7.7 \mathrm{ab}$ & $0.5 \mathrm{~b}$ & $0.4 \mathrm{~b}$ & $4.6 \mathrm{bc}$ \\
70 & 42 & 70 & 2 & $10.0 \mathrm{ab}$ & $1.1 \mathrm{~b}$ & $1.0 \mathrm{~b}$ & $8.5 \mathrm{bc}$ \\
\hline
\end{tabular}

Nota: las medias seguidas de las mismas letras no fueron significativamente diferentes al 5\%, de acuerdo a la prueba de Duncan Múltiple Range.

El análisis de correlación mostró que la capacidad de tinción del polen está positiva y significativamente correlacionada con el número de presuntos haploides por baya $(\mathrm{r}=0.343)$, el número de presuntos haploides por polinización $(\mathrm{r}=0.368)$ y el porcentaje de presuntos haploides sobre el total de semillas $(\mathrm{r}=0.409)$.

La frecuencia de polen $2 \mathrm{n}$ está correlacionada en forma positiva y 
altamente significativa con la producción de semillas $(\mathrm{r}=0.354)$, número de presuntos haploides por baya $(\mathrm{r}=0.455)$ y número de presuntos haploides por polinización $(\mathrm{r}=0.490)$, pero no está correlacionada con el porcentaje de presuntos haploides sobre el total de semillas $(r=0.064)$. Cuando se agruparon los resultados de los siete progenitores femeninos para realizar el análisis de correlación, los valores de "r" fueron significativos para la frecuencia de producción de polen $2 \mathrm{n}$ y el número de presuntos haploides por baya $(\mathrm{r}=0.77)$ y para la frecuencia de polen $2 \mathrm{n}$ y el número de presuntos haploides por polinización $(\mathrm{r}=0.8)$

\section{DISCUSIÓN}

A pesar de que la mayoría de las papas diploides cultivadas son autoincompatibles (9), fue posible obtener descendencia por autofecundación del clon de S.tuberosum Grupo Phureja IvP35. Progenies de este tipo han sido también obtenidas en China por el Dr. Li Jin Hua (comunicación personal).

Las progenies obtenidas por autofecundación mostraron, en general, los efectos característicos de la depresión por endocría: vigor reducido, floración tardía y escasa y. para algunos genotipos, baja capacidad de tinción del polen, lo que dificulta su uso como potenciales inductores de haploidía.

Dado que el clon IvP35 es homocigota dominante para el marcador "mancha en el embrión", las plantas que se obtengan por autofecundación también serán homocigóticas para los loci que controlan este carácter. Por lo tanto, la detección de presuntos haploides en cruzamientos interploides puede hacerse en forma sencilla, en el estadio de semilla.

Uno de los seis clones estudiados mostró mayor capacidad para inducir haploidía en combinación con varios progenitores femeninos que el clon IvP35. Se identificó, también, un clon cuya capacidad de inducir haploidía no difirió estadísticamente de la del clon IvP35. Ello es una indicación de que es posible obtener "buenos" polinizadores entre las progenies obtenidas por autofecundación del clon IvP35, que permitirían aumentar la eficiencia del dispositivo creado por Hougas y col. (8).

Dado que los cruzamientos interploides para identificar buenos inductores de haploidía entre las progenies obtenidas por autofecundación requieren insumes considerables en tiempo y espacio, es importante contar con una técnica rápida y sencilla para realizar el 
tamizado.

Sobre la base de los resultados de este experimento se propone que las progenies sean tamizadas, inicialmente, por la capacidad de tinción del polen y la frecuencia de polen $2 \mathrm{n}$, ya que ambos caracteres estuvieron positivamente correlacionados con el número de presuntos haploides por polinización y de presuntos haploides por baya. En una segunda etapa, los clones seleccionados deberán ser evaluados en cruzamientos interploides.

Es importante, sin embargo, tener presente que si las dispersiones para el porcentaje de tinción del polen y la frecuencia de polen $2 \mathrm{n}$ son diferentes a las observadas en este experimento debido a efectos ambientales, las correlaciones mencionadas anteriormente pueden no mantenerse.

\section{AGRADECIMIENTO}

Los autores desean expresar su agradecimiento al Dr. P. Schmiediche del CIP, por la lectura crítica de este artículo.

\section{REFERENCIAS BIBLIOGRÁFICAS}

1. Chase, S.S. 1963. Analytical breeding in Solanum tuberosum L. A scheme utilizing parthenotes and other diploid stocks. Can. J. Genet. Cytol. 5 (4): 359-363.

2. De Maine, M.J. 1982. An evaluation of the use of dihaploids and unreduced gametes in breeding for quantitative resistance to potato pathogens. J. Agr. Sci. Camb. 99:79-83.

3. Gabert, A.C. 1963. Factors influencing the frequency of haploids in the common potato (Solanum tuberosum L.). Tesis de Ph.D. University of Wisconsin, 53 p.

4. Hermsen, L.G.Th.; Verdenius, J. 1973. Selection from Solanum tuberosum group Phureja of genotypes combining high-frequency haploid induction with homozygosity for embryo-spot. Euphytica 22: 244-259.

5. Hermunstad, S.; Peloquin, S. J. 1985. Germplasm enhancement with potato haploids. J. Hered. 76:463-467.

6. Hougas, R.W.; Peloquin, S.J. 1958. The potential of potato haploids in breeding and genetic research. Am. Potato J. 35: 701-707. 
7. Hougas, R.W.; Peloquin, S.J.; Gabert, A.C. 1964. Effect of seed parent and pollinator on frequency of haploids in Solanum tuberosum. Crop Sci. 4: 593-595.

8. Hougas, R.; Peloquin, S.J.; Ross, R. 1958. Haploids of the common potato. J. Hered. 49:103-106.

9. Howard, H. W. 1970. Genetics of the potato Solanum tuberosum. SpringerVerlag: Berlín. 126p.

10. Iwanaga, M. 1980. Breeding at the 2x level for combined pest and disease resistance using wild species and extracted haploids from selected tetraploid clones. In: Útilization of the genetic resources of the potato. III Rep. Plann. Conf. 1980.123 p.

11. Iwanaga M. 1984. Potato Breeding for combined resistance to tropical pests by the ploidy level manipulation approach: progress in extraction of haploids with male fertility and $2 \mathrm{n}$ pollen. In: $6^{\text {th }}$ Symp. Int. Soc. for Tropical Root Crops. Lima, CIP. 1983. 481-486 p.

12. Marks, G.E. 1954. An acetocarmine glycerol jelly for use in pollen fertility counts. Stain Technol. 29: 277.

13. Mendiburu, A.O.; Camadro, E.L. 1988. Uso de haploides en el mejoramiento genético de la papa. In: IICA-BID-PROCIANDINO 1988. II Seminario Nuevos Enfoques para el mejoramiento de la papa. B. Ramakrishna (ed.) Quito, Ecuador.

14. Mendiburu, A.O.; Peloquin, S.J.; Mok D.W.S,. 1974. Potato Breeding with haploids and 2n gametes. pp. 249-258. In: Kasha, K.J. (ed.), Proc. I't Int. Symp. Haploids in Higher Plants. Guelph, Canadá: University of Guelph.

15. Rowe, R. 1974. Methods of producing haploids: parthenogenesis following

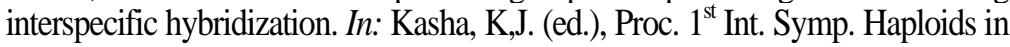
Higher Plants. Guelph,Canada: University of Guelph. 